\title{
Man-machine interactions in advanced manufacturing systems
}

\author{
Przemysław Oborski \\ Warsaw University of Technology, \\ Institute of Manufacturing Technology, \\ ul. Narbutta 86, 02-524 Warsaw, Poland \\ e-mail: P.Oborski@wip.pw.edu.pl
}

\begin{abstract}
Development of modern machines and production equipment, supported by advanced control systems, based on recent achievements of computer and software technology is necessary to fulfil clients requirements. Significant number of manufacturing systems can work automatically with limited contribution of employees. However even in advanced manufacturing systems still one of the most important factors is human being. Usually the whole system performance depends on human decisions, the significance of them is higher than in the past, because of more complex and costly production systems. In such a situation, the importance of efficient utilisation of manufacturing equipment by proper man-machine interaction is necessary. The paper presents the problem of man-machine interactions, as well as the attempt to model human behaviour. The interaction media have been explained and short survey of research in this field has been done. The aim of the paper is to order the knowledge about man-machine interactions.
\end{abstract}

Keywords: manufacturing systems, man-machine interaction, human factor, computer integrated production, control systems.

\section{Introduction}

Competitiveness and effective utilisation of the present and future, more computerised machines and manufacturing systems can be achieved by putting higher stress on the human factor. Proper co-operation of human and advanced intelligent devices supporting production, like process and machine monitoring will be important 
part of production in the near future. In designing of control systems and new machines, advantages and disadvantages of human operator have to be taken into account. Better work organisation should ensure high motivation, increase competencies, personnel stability and human work efficiency.

It seems to be obvious that the new approach to the process of man-machine interaction should be developed. It has to be based on the latest achievements of the software engineering, new unconventional possibilities of hardware systems and deep knowledge about human behaviour. Better utilisation of human and modern manufacturing systems' advantages by proper man-machine interaction design should be the aim of the multidisciplinary research.

\section{Interaction of human software systems}

The characteristics of manufacturing, decides that it has to be considered as a discrete production. The number and interrelations of control parameters and constrains decide that discrete production can be treated as a complex system. The main features of such systems are [1]:

- Large number of components

- Multiplicity of components' types

- Highly coupled components

- Presence of disturbances

Full automation of control functions in production appears to be impossible without loosing flexibility and malfunctions' resistance, what is the consequence of the complexity of present manufacturing systems. High performance, products quality, systems flexibility required from one side and complex problems solving, experience based learning from the other side require strict co-operation of the information technology and human factor. However, to be effective such co-operation has to take into account both human and information systems features.

The human and information system co-operation is strongly dependent on behaviour of a man and computer system. Human operator has very unique natural abilities that decide about his or her important role in manufacturing. The most important are: experience based self-learning, adaptation to new situations, high abilities of manual manipulation, very efficient sense feedback (eyesight, hearing, etc.), possibility of innovative solution application, foreseeing of controlled system behaviour based on 
current observations, possibility of reactions on unforeseen situations. Those features decide about very strong advantages of man in both machine control and management level.

Table 1. Influence of human characteristic on information systems (based on [2]).

\begin{tabular}{|l|l|}
\hline \multicolumn{1}{|c|}{ Human characteristic } & \multicolumn{1}{c|}{ Constraint put upon IT-systems } \\
\hline $\begin{array}{l}\text { Difficult work with high number of } \\
\text { detailed data }\end{array}$ & $\begin{array}{l}\text { Filter data, represent aggregated data } \\
\text { and charts }\end{array}$ \\
\hline $\begin{array}{l}\text { Low communication bandwidth, limiting } \\
\text { the transfer of information between IT } \\
\text { system and man }\end{array}$ & $\begin{array}{l}\text { Allow for the most optimal user- } \\
\text { interface, using new technology for input } \\
\text { and output of data }\end{array}$ \\
\hline $\begin{array}{l}\text { Hard context switch when going from } \\
\text { one task to another }\end{array}$ & $\begin{array}{l}\text { Not demand short, diverse tasks of the } \\
\text { human workers }\end{array}$ \\
\hline $\begin{array}{l}\text { Motivation problem when autonomy is } \\
\text { too much restricted }\end{array}$ & $\begin{array}{l}\text { Allow human workers for some decision } \\
\text { freedom }\end{array}$ \\
\hline $\begin{array}{l}\text { Making mistakes, forgetting input the } \\
\text { data }\end{array}$ & \begin{tabular}{l} 
Check for data consistency \\
\hline Slow response time to events
\end{tabular} \\
\hline $\begin{array}{l}\text { Low predictability of operation times of } \\
\text { manual tasks }\end{array}$ & $\begin{array}{l}\text { Take it into account, if possible based } \\
\text { opon historical information }\end{array}$ \\
\hline
\end{tabular}

The most important drawbacks of human being are: limited number of information processed at the same time, difficulty or impossibility of quickly changing process control, no deterministic behaviour, growing malfunctions if tasks are changing too often or are monotonous. The human efficiency decreases when the aim of work is not understood or he/she can not take decisions about it [3].

Some of pointed drawbacks can be eliminated or their influence on manufacturing process can be limited by proper work organisation. Operator should know the aim of his work and should be able to take even limited decisions concerning his work place. In the case of human-software system co-operation the graphical interface should be designed with taking into account its usefulness and easy operation by particular operator or groups of operators [4]. However, computer applications and graphical 
interfaces very often are designed by programmers that do not know specific of particular workplace and human computer system co-operation problem [5].

When software systems are built, too often the main stress is put on preparation of information but not on its presentation. Computer system operators are very often regarded as an "extended computer", able to calculate, understand and synthesise large amounts of data, which they can not do [1]. The significant decrease in efficiency and opinion that advanced software systems are not so useful in production as they should be, are the result of such a situation [6].

Present computer information systems have very high speed and processor capacity, high accuracy, and ability to store and process large amount of data. The main drawbacks of information systems are: work according to stiff algorithms, lack of innovative reactions and real intelligence defined as skilfulness of new algorithms creation. Important limitation in the case of human co-operation is a necessity of precise task definition and necessity of accurate data input.

Human computer-system co-operation is based on the integration of two systems with completely different features [7]. The intelligent man being able to take intuitive, actions, solve diverse problems and learn by experience is on one side. On the other side is the information system that can process large amount of data in short time, has detailed information and short response time. Such integration can be risky, but it gives possibility of complementary co-operation in the case of proper computer system designing. The impact of human behaviour on the computer system structure has been shown in table 1 .

\section{Man-machine interaction}

Nowadays most of machines used in manufacturing has special control systems. Such a system can control realisation of most of machine functions. The control systems can be uncomplicated, based on simple PLC (Programmable Logical Control) or based on advanced mutilevel hierarchical control models [8]. Such systems can be responsible for control and supervision of the advanced machines and process. However, all kinds of machine control systems have to be supervised by human operator. He is necessary in complex problems solving, like in the case on malfunctions and brake downs [3]. 
Machine operator may co-operate with machine or process through the system control and out side the control system, as well. This matter was discussed by Stahre, the interaction model was proposed by Sheridan [9].

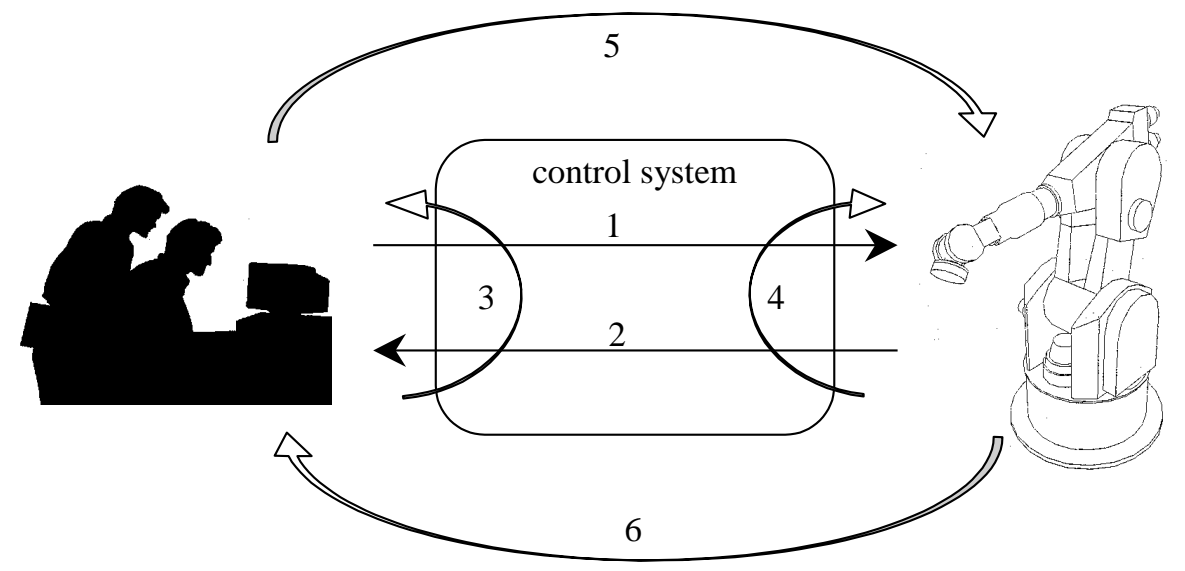

Fig. 1. Man-machine communication model (based on [9]).

The model points six kinds of interactions between the human operator, computerised control system and controlled machine (fig. 1):

1. Operator orders the process indirectly through the computer system

2. Operator receives the process status indirectly

3. Operator asks for or receives information from the computer

4. Process asks for or receives information from the computer

5. Operator intervenes directly into the process

6. Operator observes the process by his own sense

In the above model interactions from (1) to (4) are controlled by the computer system. In other words, the system designer has foreseen them. They should be appropriated to the controlled system and operators requirements. The most difficult for control system are direct operator interactions into the controlled system or machine (interactions (5) and (6)). Such interactions usually occur in the case of the machine or process incorrect behaviour, when the man intervention is necessary.

Man-machine interaction can be realised in different ways, also outside of the control systems. Properly designed machine control systems should not only allow for interactions in predictable situations. It should be robust for unpredictable situations like direct human intervention into the controlled machine or process as well. It is especially important in automated machines and monitored machining processes [10]. 


\section{The model of human operator}

Manufacturing systems' designers usually focus their attention on proper material and information processing, but do not appreciate enough influence of human behaviour on the system performance. As a result of such approach the system does not work properly very often, because of man-machine co-operation problems. Some research work has been done in this field in the past, however most of them were focused on ergonomics or psychology problems [11][12][13].

Elaboration of the mathematical model, describing human behaviour in manufacturing system would be very important. Basing on such a model, development of a simulation software as a support for designers of manufacturing systems or its components would be possible. However, the problem of human behaviour modelling is very difficult. Human being behaviour is strongly no deterministic. As a result of it, equations describing human behaviour can not model a man or woman exactly. In this chapter some approach was done to describe such a problem, however the aim of proposed description is rather to point some important relations between factors describing a man, than to build the exact mathematical model.

Factors characterising human control work in system should be introduced at first. They should be minimised.

$\tau$ - control delay - can be characterised as a time between abnormal situation appearance and getting system to the required state: $\tau \geq 0$.

$\mathrm{t}$ - human reaction time - describes operator's behaviour, can be characterised as a time between abnormal situation appearance and a control decision taken by operator: $\mathrm{t} \geq 0$.

$\eta$ - system inertia - time between control decision with control action and reaching the proper state by the system: $\eta \geq 0$.

Description of human behaviour requires definition of significant number of nondimensional factors, that point the most important features of human being in manufacturing system:

$\xi$ - human decision correctness: $\xi \geq 0, \xi \Uparrow$ (is growing) together with growing the correctness of taken decision,

$\alpha$-problem difficulty: $\alpha \geq 0, \alpha \Uparrow$ with growing the solving problem difficulty, 
$\beta$ - human tiredness: $\beta \geq 0, \beta$ 介 when operator tiredness increases,

$\chi$ - fears for bad decision taking: $\chi \geq 0, \chi \Uparrow$ with growing the fears of bad decision taking,

$\delta$ - human experience: $\delta \geq 0, \delta \Uparrow$ when the operator experience increases,

$\varepsilon$ - human involvement: $\varepsilon \geq 0, \varepsilon \Uparrow$ with growing the operator involvement in work,

$\phi$ - problem understanding: $\phi \geq 0, \phi \Uparrow$ when problem understanding increases,

$v$ - education: $v \geq 0, v \Uparrow$ with growing the education level,

$\kappa$ - friendliness of control system $\kappa \geq 0, \kappa \Uparrow$ when system is more user friendly,

$\gamma$ - work conditions: $\gamma \geq 0, \gamma \Uparrow$ with improvement of work conditions quality,

$\mu$ - work motivation: $\mu \geq 0, \mu \Uparrow$ when the operator motivation to work increases,

$v$ - work load: $v \geq 0, v \Uparrow$ with growing metal or manual human work load,

$\theta$ - problem typicality: $\theta \geq 0, \theta \Uparrow$ when problem is not typical,

$\psi$ - responsibility: $\psi \geq 0, \psi \Uparrow$ when operator work conscientiously,

$\lambda$ - company goals understanding: $\lambda \geq 0, \lambda \Uparrow$ with growing the company goals understanding and approving,

$\pi$ - working environment: $\pi \geq 0, \pi \Uparrow$ with growing quality of working environment,

$\rho$ - gratification: $\rho \geq 0, \rho \Uparrow$ with increase in gratification acceptance,

$\sigma$ - additional motivation factors (for example: career opportunity, training's, etc.): $\sigma$

$\geq 0, \sigma \Uparrow$ with growing of the motivation factors,

$\mathrm{T}$ - summary working time on given or similar stand,

$\mathrm{T}_{\mathrm{d}}$-working time on given day,

$\mathrm{R}$ - kind of work,

W - operator age,

$\mathrm{O}$ - personality.

After definition of the most important human features, the general formulas modelling relations between factors describing human behaviour can be done:

Control decision delay:

$$
\tau=\mathrm{t}+\eta
$$

Human reaction time:

$$
\mathrm{t}=\frac{\alpha+\beta+\chi+\theta}{\delta+\varepsilon+\phi+\gamma+\xi+\kappa}
$$


Decision quality:

$$
\xi=\frac{\delta+\varepsilon+\phi+\mu+\psi+\theta+\kappa}{\alpha+\gamma+v+\chi+\beta}
$$

Experience:

$$
\delta=\mathrm{f}(\mathrm{T}, \varepsilon, \gamma, \mu) \quad \forall \mathrm{O}, \forall \mathrm{W}, \forall \mathrm{R} ;
$$

Involvement in work:

$$
\varepsilon=\mathrm{f}(\mu, \gamma, \mathrm{v}) \quad \forall \mathrm{O}, \forall \mathrm{W}, \forall \mathrm{R}
$$

Human tiredness:

$$
\beta=\mathrm{f}\left(\mathrm{T}_{\mathrm{d}}, \gamma, \mathrm{v}, \mathrm{R}, \mathrm{W}, \varepsilon\right)
$$

Motivation:

$$
\mu=\mathrm{f}(\lambda, \pi, \mathrm{W}, v, \rho, \sigma)
$$

Reaction time of control system supported by human decision:

$$
T_{c}=f\left(C_{h}+C_{p}\right)
$$

where:

$\mathrm{C}_{\mathrm{h}}$ - human factors described above

$\mathrm{C}_{\mathrm{h}}$-factor that are not dependent on human behaviour (for example: user friendliness of system control, control system reaction time, etc.)

The aim of proposed model is to point the most important features of human behaviour and to show relations between them. Special tests have to be the next step of research in these directions. The result of those tests should allow to build more detailed model of man by elaboration of weights of particular factors. Model of human behaviour could be used by manufacturing systems or its components designers and managers responsible for work organisation as well.

\section{Interaction media}

The interaction process between people and machines or information systems in manufacturing can be realised by different types of media [14]. Usually, the communication takes place in two directions: from operator to machine and from 
machine to operator. From the machine or system point of view the interaction from a man to machine is an input, the opposite direction from machine to a man is an output.

The most common communication approach is using of the conventional computer input/output devices. The input is usually based on the control of human body movements. The most common is the control of fingers and hands movements and tactile. However, it is also possible to monitor movements of other parts of body like: head and eye, legs, etc.. The input to the system can based also on the voice commands.

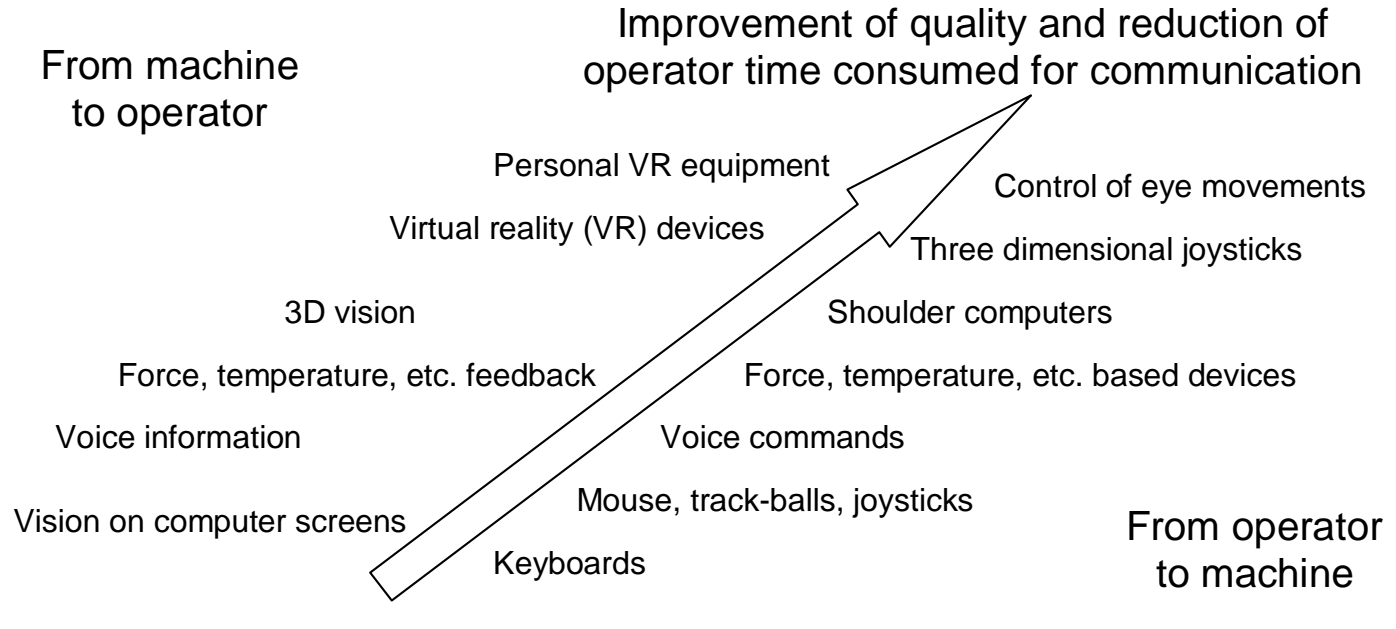

Fig. 2. Man-machine interaction media.

The system output is usually realised by the vision as a transmission medium, but using the audio systems is also popular. In the special machines other mediums, like force or temperature signals and tactile feedback can be used, as well.

The research in the field of the man-machine interaction is focused on development of the media that enable the best information exchange. Communication media suited to needs of the particular process should not engage the operator in the information exchange too much. The operator should be focused on solving problems appearing in the controlled system, but not on communication with it.

Computer terminals are the most popular input and output devices for advanced man machine interactions. Usually they include: the conventional keyboard, mouse, trackball, computer pens. Research carried to modify those devices were discussed by Agah [14]. The most promising research for manufacturing systems, are focused on elaboration of shoulder computers and input devices supported by voice 
communication. Solutions for control and teaching manufacturing robots like spaceballs and three-dimensional joysticks, seem to be very interesting, as well.

The most popular output devices for control systems are visual displays. They can be used for presentation of data and images. The data and images from the real and virtual world can be presented on the visual displays. The real world data and images are usually presented on the screens of machine control systems and supervisory manufacturing management systems. The research has shown that, at the same time a few windows presenting different data can be open on the one screen [15], however the data should be presented in the simple and easy to understand way. Presentation of images can allow for easier data understanding. It allows also for tele-monitoring, which is very useful in the case of automated manufacturing systems or distributed production.

Presentation of virtual data and images that are results of various simulations may be very helpful for operators. Such solution can be applied for caching the correctness of new manufacturing process, $\mathrm{NC}$ and robot control programs. The visual presentation of the simulation results is used very often in the case of whole manufacturing systems simulation for optimising the system load and production schedule [16]. The latest research in this field are focused on elaboration of the three-dimensional visual presentation of the virtual environment, head-mounted displays and stero-graphics video presentation for operator control stations [14].

Various audio displays are used very often in the machine-operator communication. They can present the real sounds, virtual sounds generated by the computer and data presented in easy to understand, sound form.

The operator-machine communication can be supported by voice commands systems, as well. Such systems can recognise the human speech and sometimes are capable of gaining an additional information from the human voice. Very often they allow for the operation time reduction by quicker communication than in the case of the traditional computer communication devices. They can be used in dialog management systems, virtual reality systems, but its application on the shop floor can sometimes be difficult because of various kinds of noise.

Other communication media that could be implemented in human-machine information exchange are: force (communication from operator to system), force feedback (communication from system to operator), tactile, temperature, temperature 
feedback. Force, as a communication way can be used in robot control and teaching, however it seams that other pointed media can be applied in manufacturing only in very special applications.

\section{Recent research on human-machine interactions}

The application of the advanced human-systems interactions covers wide range of tasks. The aim of this chapter is to give a short review of research that were focused on interaction problem in manufacturing. For those who need more general information the complex taxonomy of research on human interactions with intelligent systems made by Agah can be advised [14].

Most of papers that touched the problem of man-system co-operation describe particular problem solving. However, some grouping of the research can be done.

Man-machine interaction problems in advanced manufacturing were discussed by Stahre [9]. Analyse of data collected from almost hundred United States manufacturing companies to investigate association between human factors and the success of advanced manufacturing systems was done by Udo [17].

The problem of design of man-machine interfaces for co-operative supervision and control by several users was discussed by Johannsen [18]. He also touched the problem of knowledge-based interface design [4]. Designing of man-machine interfaces to match the user's mental model was described by Fuchs [15]. Development of an analysis support system for man-machine system design based on simulation and allowing for its evaluation from various viewpoints of human operator is explained by Yoshikawa [12].

The problem of integration of responsive discrete management system, with human operator in discrete production has been presented by Trentesaux [1]. Author of the paper pointed some ways for integrating man and new conceptions (multi-agent architecture, multi-criteria and distributed decision support, advanced display) of supporting complex manufacturing systems. The role of human factor in management area is discussed by Barthelemy. He emphasises the role of human factor in Decision Support Systems and related assisting tools that can be used in the field of Operational Research [19]

General problems of human error modelling were pointed by Johnson [20]. The paper is not focused directly on human errors in particular industry, however it can be useful for analysing of decision quality in manufacturing. For benchmarking research of 
an error modelling and man-machine interaction problem, the paper describing an integrated simulation for the analysis of pilot-aeroplane interactions can be studied [13].

The man-machine interaction problem from ergonomic point of view was investigated by Jung [11]. A man-machine interface model was developed in which the visibility and reach tests are embodied. The model aims at a support for various machine designers.

Some papers describe the planing problems like optimal operator assignment and cell loading in labor-intensive manufacturing cells, for example Suer [21].

For those who are interested in Intelligent Systems application in advanced manufacturing systems the review of developments and future prospects of Intelligent Systems in manufacturing can be advised [22]. The review put stress on human aspects in Intelligent Manufacturing Systems as well.

\section{Conclusions}

In manufacturing systems proper co-operation of human and information/control systems supported by Artificial Intelligence can significantly improve whole production performance. In advanced manufacturing systems human factor plays even more important role than in the past, in spite of predictions from seventies that in fully automated production, operators would no longer be needed. However, still not everybody responsible for systems and machines interface designing appreciate the human operator significance. Very often the information systems interfaces are designed by programmers who don't understand the problem of man-machine interaction. Such an attitude makes impossible optimal utilisation of advantages of the human operator. Wrong design of interaction process too often results in lower then expected manufacturing systems performance.

The most important factors of man-machine interaction in advanced manufacturing systems have been pointed in the paper. The attempt to propose the way of human modelling, decision quality and man-machine interaction description has been done and the socio-technical design idea was described. It can be very useful in designing of interactions of social and technical systems.

In advanced manufacturing systems the significant stress should be put on the problem of man-machine and man-computer systems co-operation. The aim of the paper was to do some attempt to point the most important things in this field. 


\section{References}

1. Trentesaux D., Moray N., Tahon C. "Integration of the human operator into responsive discrete production management systems", European Journal of Operational Research, Vol. 109 (1998), pp. 342-361.

2. Wyns J. "Reference architecture for holonic manufacturing systems - the key to support evolution and reconfiguration", PhD thesis, KU Leuven, Belgium 1999.

3. Mikler J., Hadeby H., Kjellberg A., Sohlenius G. „Towards Profitable Persistent Manufacturing. Human Factors in Overcoming Disturbances in Production Systems", The International Journal of Advanced Manufacturing Technology, Springer-Verlag London 1999, 15 p.749-756.

4. Johannsen G. "Knowledge-based design of human-machine interfaces", Control Eng. Practice, Vol. 3, No 2 pp. 267-273, 1995.

5. Oborski P., Buczacki A. „Process oriented organisation and human factors in computer integrated manufacturing", Proceedings of the International Conference: Computer Integrated Manufacturing 2001 - CIM'01, Zakopane 7-8.03.2001.

6. Gunasekaran A., Thevarajah K. "Implications of Computer-Integrated Manufacturing in Small and Medium Enterprises: An Empirical Investigation”, The International Journal of Advanced Manufacturing Technology; 15: 251-260; Springer-Verlag London 1999.

7. Oborski P., Szafarczyk M. „Organisation and Control at the Basic Manufacturing Level with Human-Computer Integration", Advances in Manufacturing Science and Technology, Vol. 25, No. 1, 2001, p.5-15.

8. Bongaerts L., Monostori L., McFarlane D., Kadar B. "Hierarchy in Distributed Shop Floor Control", Computers in Industry 43 (2000) 123-137.

9. Stahre J., "Evalauating human/machine interaction problems in advanced manufacturing", Computer Integrated Manufacturing Systems, Vol. 8, No 2 p. 143150, 1995.

10. Sokolowski A., Kosmol J. "Selected examples of cutting process monitoring and diagnostics", Materials Processing Technology, 113 (2001) pp. 322-330.

11. Jung E.S., Kee D. “A man-machine interface model with improved visibility and reach functions", Computers ind. Engng Vo. 30, No. 3, pp. 475-486, 1996. 
12. Yoshikawa H., Nakagawa T., Nakatani Y., Furuta T., Hasegawa A. "Development of an analysis support system for man-machine system design information", Control Eng. Practice, Vol. 5, No. 3, pp.417-425, 1997.

13. Cacclabue P.C., Cojazzi G. "An integrated simulation approach for the analysis of pilot-aeroplane interaction”, Contorl Eng. Practices, Vol.3, No.2, pp.257-266, 1995.

14. Agah A. "Human interactions with intelligent systems: research taxonomy", Computers and Electrical Engineering, 27 (2001), p. 71-107.

15. Fuchs-Frohnhofen P., Hartmann E.A., Brandt D., Weydandt D. "Design humanmachine interfaces to match the user's mental models", Control Eng. In Practice, Vol. 4No 1, pp. 13-18, 1996.

16. Gregor M., Kosturiak J., Hromada J., Balcercik V. "How the Simulation Helps to Improve Manufacturing Systems", Proceedings of The Second World Congress on Intelligent Manufacturing Processes \& Systems, Budapest, June 10-13.1997, p.110115.

17. Udo G., Ebiefung A. "Human factors affecting the success of Advanced Manufacturing Systems”, Computers \& Industrial Engineering, 37 (1999), p. 297 300 .

18. Johannsen G. "Conceptual design of multi-human machine interfaces", Control Eng. Practice, Vol. 5, No 3 pp. 349-361, 1997.

19. Barthelemy J.P., Bisdorff R., Coppin G. "Human centered process and decision support systems”, European Journal of Operational Research, Vol. 136 (2002), pp. 233-252.

20. Johnson C. "Why human error modelling has failed to help systems developement", Interacting with Computers, 11 (1999), p. 571-524.

21. Suer G. A. "Optimal operator assignment and cell loading in labor-intensive manufacturing cells", Computers Ind. Eng. Vol. 31, No 1/2 pp. 155-158, 1996.

22. Meziane F., Vadera S., Kobbacy K., Proudlove N. "Intelligent systems in manufacturing: current developments and future prospects", Integrated Manufacturing Systems, 11/4 [2000], pp. 218-238. 